\title{
Carbene in cupredoxin protein scaffolds: replacement of a histidine ligand in the active site substantially alters copper redox properties
}

\author{
Matteo Planchestainer, ${ }^{[a]}$ Nathalie Segaud, ${ }^{[b]}$ Muralidharan Shanmugam, ${ }^{[c]}$ Jonathan McMaster, ${ }^{[a]}$ \\ Francesca Paradisi ${ }^{*[a]}$ and Martin Albrecht ${ }^{*[b]}$
}

\begin{abstract}
N-heterocyclic carbene (NHC) ligands have had a major impact in homogeneous catalysis, however, their potential role in biological systems is essentially unexplored. Here we replaced a copper-coordinating histidine (His) in the active site of azurin with exogenous dimethyl-imidazolylidene; this NHC rapidly restores the type-1 $\mathrm{Cu}$ center with spectroscopic properties (EPR, UV-vis) that are identical to those from $\mathrm{N}$ coordination of the His in the wild type. However, the introduction of the NHC markedly alters the redox potential of the metal, key functionality of this blue copper protein. These results suggest that C-bonding for histidine is plausible and a potentially relevant bonding mode of redox-active metalloenzymes in their (transient) active states.
\end{abstract}

$\mathrm{N}$-heterocyclic carbenes (NHCs) have had a major impact in catalysis, ${ }^{[1-5]}$ and to some extent also in materials science. ${ }^{[6,7]}$ Their biological application has been limited to antimicrobial ${ }^{[8]}$ and some anticancer activity, ${ }^{[9]}$ and, remarkably, the impact of NHC ligands in biocatalysis is virtually unexplored. The only report on combining organometallic carbene chemistry with proteins involves the introduction of a fully synthetic NHC ruthenium complex into streptavidine for olefin metathesis, ${ }^{[10]}$ yet the modification of a natural metalloenzyme active site with a NHC ligand has no precedent. The introduction of an abiotic NHC ligand at the metal center in metalloenzymes has significant

[*] [a] Dr. M. Planchestainer, Prof. J. McMaster, Prof. F. Paradisi

School of Chemistry

University of Nottingham

University Park, Nottingham, NG7 2RD, UK

Tel: +44 1157486267

[b] Dr. N. Segaud, Prof. M. Albrecht,

Department of Chemistry \& Biochemistry

Universität Bern

Freiestrasse 3, 3012 Bern, Switzerland

Tel: +41316314644

[c] Dr. M. Shanmugam

Manchester Institute of Biotechnology

University of Manchester

131 Princess St, Manchester, M1 7DN, UK

Email: francesca.paradisi@nottingham.ac.uk martin.albrecht@dcb.unibe.ch

[**] We thank Dr. A.-K. Liliensiek and Dr. G. Gucciardo for preliminary work and the European Research Council through a Starting Grant (StG 208561) and a Consolidator grant (CoG 615653) and by HEA Ireland (fellowship to M.P.) for generous financial support.

Supporting information for this article is available on the WWW under http://www.angewandte.org or from the author. potential, especially when considering the promoting role of carbenes in homogeneous catalysis. Such an approach is complementary to the introduction of an abiotic metal center into heme cofactors, ${ }^{[11]}$ or the evolution of enzymes to impart nonnatural reactivities ${ }^{[12]}$ and constitutes a new method to expand the scope of application for metalloenzymes.

The similarity of NHCs with histidine (His), in terms of structure and origin (Fig 1), makes the substitution of His in a metalloenzyme active site by a NHC ligand an obvious strategy to probe the impact of NHCs in metalloenzymes. Histidine is ubiquitous as a ligating amino acid in metalloenzymes and binds to the metal center through its imidazole side chain. ${ }^{[13,14]}$ Due to the markedly different donor properties of an $\mathrm{N}$-coordinated imidazole (weak $\pi$-acidic imine donor) in His $v s \mathrm{NHC}$ as a $C$ bound analogue (strong $\sigma$-donor),${ }^{[1,2]}$ carbene-type bonding of the imidazole heterocycle is expected to have substantial implications for the functional role of the coordinated metal center and/or the redox processes of metal centers involved in electron transfer reactions. ${ }^{[15-18]}$
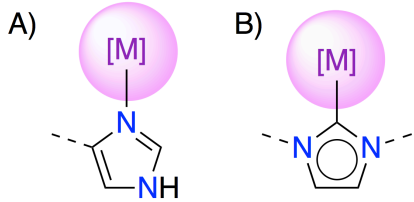

Fig 1. Metal coordination of imidazole A) through nitrogen as established for His, and B) through carbon as in NHC complexes.

As a proof of concept, we have considered NHC bonding at the $\mathrm{Cu}$ center in Azurin (Azu). Azurin has been well characterized and acts as electron shuttle to redox enzymes, such as nitrite reductase. ${ }^{[19-24]}$ Azu contains a type 1 (T1) Cu center in which the $\mathrm{Cu}^{\mathrm{II}}$ is coordinated by four amino acids, His 117, His46, Met121 and Cys112, together with a weak interaction involving the carbonyl group of Gly45 (Fig 2). His 117 resides in a shallow depression of the protein, close to the surface and easily accessible by the solvent. ${ }^{[25]}$ The mutation of His 117 , to a glycine has shown significant flexibility for the introduction of exogenous ligands; the His117Gly inactive variant has been successfully reconstituted with imidazole and imidazole derivatives without distorting the tertiary structure of the protein. ${ }^{[26]}$

Here we have exploited the $\mathrm{H} 117 \mathrm{G}$ Azu mutant for the introduction of an $\mathrm{N}$-heterocyclic carbene to investigate the implications of a C-bonding ligand as a surrogate for histidine at a T1 copper center. ${ }^{[27]}$ We provide compelling evidence that carbene coordination significantly facilitates electron transfer to the copper center, while spectroscopically, carbene bonding is barely distinguishable from $\mathrm{N}$-coordination of the imidazole heterocycle. The modulation of the redox potentials suggests a potential relevance for C-bonding ligands in metalloenzymemediated electron transfer processes. 


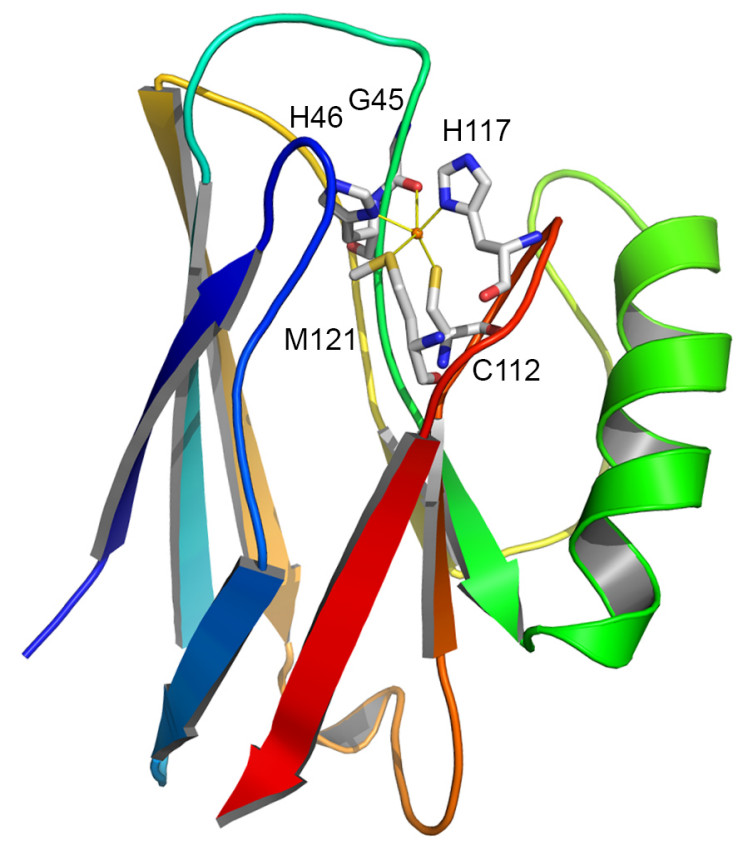

Fig 2. Schematic representation of azurin (from $P$. aruginosa) illustrating the surface protrusion of the copper-binding imidazole ring of His117 (PDB 3U25, reference [24]).

Clones of the wild type (WT) and $\mathrm{H} 117 \mathrm{G}$ variants of azurin $^{[28,29]}$ were used as templates to generate a cleavable polyHis-tag version of both proteins (see SI). This approach led to enhanced protein expression and a one-step purification, without perturbing the signature spectroscopic and electrochemical properties of the proteins. ${ }^{[30]}$ Samples of the WT and H117G mutant azurin were purified to homogeneity (see supplementary information, Fig. S6, S7) and their structural integrity ${ }^{[31]}$ was unambiguously verified by mass spectrometry (Fig. S5). The ability of the mutant to bind $\mathrm{Cu}^{2+}$ in the presence of $N$-methyl imidazole (NMI; Scheme 1) was verified by UV-vis and EPR spectroscopies, as well as by electrochemistry (Fig. S8, S9, S15). The coordination of NMI was supported by the re-establishment of the reduction potential of the WT form; the cathodic potential $\left(E_{\mathrm{pc}}\right)$ of the $\mathrm{H} 117 \mathrm{G} \sim \mathrm{NMI}$ mutant was at $+0.34 \mathrm{~V}$ vs normal hydrogen electrode (NHE), essentially the same potential as that observed for the WT $\left(E_{\mathrm{pc}}=+0.33 \mathrm{~V} v s \mathrm{NHE}\right)$. Comparison of frozen solution X-band EPR spectra of $\mathrm{H} 117 \mathrm{G} \sim \mathrm{H}_{2} \mathrm{O}$ and H117G NMI mutant samples measured at $20 \mathrm{~K}$ (Fig. S15) revealed the conversion of $\mathrm{T} 2 \mathrm{Cu} \mathrm{EPR}$ signal observed for the $\mathrm{H} 117 \mathrm{G} \sim \mathrm{H}_{2} \mathrm{O}$ into a classic $\mathrm{T} 1$ signal for $\mathrm{H} 117 \mathrm{G} \sim \mathrm{NMI}$, reconstituting the WT signature of the $\mathrm{T} 1 \mathrm{Cu}$ center $\left(\mathrm{g}_{\|}=2.268\right.$, $\left.A_{\|}=57.4 \times 10^{-4} \mathrm{~cm}^{-1}\right)$. These observations are in excellent agreement with the literature data and confirm that the $\mathrm{H} 117 \mathrm{G}$ mutation does not appear to affect the structure of the protein significantly, nor the ability to restore electron transfer function following the coordination of NMI. ${ }^{[28,29]}$

Dimethylimidazolium carboxylate is the ideal precursor for the generation of an $\mathrm{N}$-heterocyclic carbene ${ }^{[32,33]}$ at the $\mathrm{Cu}$ center. Previous studies have demonstrated that carbene bonding to small molecule $\mathrm{Cu}^{\mathrm{I}}$ complexes is established via the decarboxylation of this precursor, ${ }^{[34]}$ and we have now demonstrated the suitability of this decarboxylation protocol for the formation of high-valent $\mathrm{Cu}^{\mathrm{II}}$ NHC complexes. ${ }^{[30]}$ Therefore, we adopted this approach to install an exogenous carbene ligand at the $\mathrm{Cu}$ center of $\mathrm{Azu}$ H117G (H117G NHC) by the decarboxylation of $N, N$ 'dimethylimidazolium carboxylate (Scheme 1). We used an excess of the pure imidazolium-carboxylate (250 equivalent) ${ }^{[30]}$ to promote the binding of the carbene to the mutagenized $\mathrm{Cu}$ site.
This methodology is highly tolerant to water, ${ }^{[34]}$ and the reaction was conveniently performed in an aqueous MES buffer. The addition of the carbene precursor rapidly induced a color change of the protein in solution from colorless to blue, essentially identical to the change observed when reconstituting the $\mathrm{T} 1 \mathrm{Cu}$ center of the $\mathrm{H} 117 \mathrm{G} \sim \mathrm{H}_{2} \mathrm{O}$ mutant by adding exogenous NMI (see above). Characteristically, the UV-vis spectrum of $\mathrm{H} 117 \mathrm{G} \sim \mathrm{NHC}$ shows a strong absorbance with $\lambda_{\max }=629 \mathrm{~nm}\left(\varepsilon=4.4 \mathrm{mM}^{-1} \mathrm{~cm}^{-}\right.$ $\left.{ }^{1}\right)$ and bleaching of the absorption band around $420 \mathrm{~nm}$.
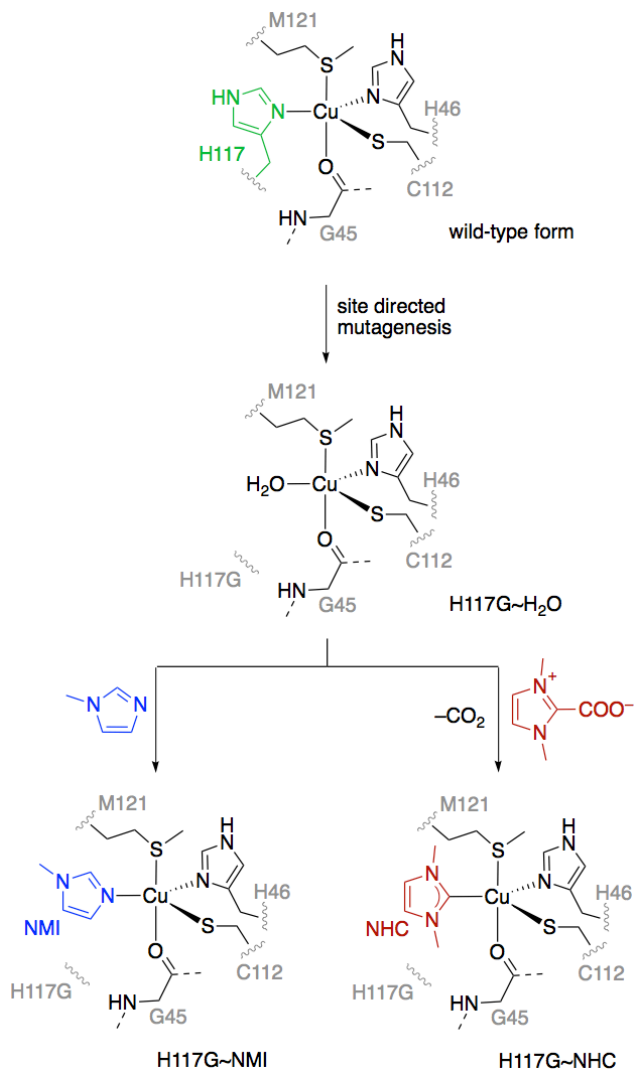

Scheme 1. Schematic representation of the active site of the azurin WT form, and the synthesis of the H117G mutants containing an NMI and a NHC ligand as mimics of $N$ - and $C$ bonding modes of His, respectively.

The titration of holo $\mathrm{H} 117 \mathrm{G} \sim \mathrm{H}_{2} \mathrm{O}$ with the carboxylate NHC ligand precursor was monitored by UV-vis spectroscopy. Incomplete restoration of the absorbance at $c a .630 \mathrm{~nm}$ following the treatment of holo $\mathrm{H} 117 \mathrm{G} \sim \mathrm{H}_{2} \mathrm{O}$ with the carbene precursor was readily detected by the subsequent addition of NMI, which transformed any residual solvent-ligated $\mathrm{Cu}$ site to the NMI adduct and increased the absorption at $630 \mathrm{~nm}$. While NMI bonding was complete when using 25 equiv. of the imidazole (H117G mutant typically at $2 \mathrm{mM}$ ), NHC coordination was only partial (ca. 20\%, Fig S10, S11). The conversion is raised substantially when using 250 equiv. of imidazolium carboxylate, and complete carbene binding at the active site was indicated by the absence of any significant absorption change upon addition of NMI. Higher concentrations of carbene precursor resulted in rapid bleaching of the sample, suggesting the reduction or decoordination of the copper from the azurin active site. 250 equivalents offer optimum conditions to induce carbene bonding sufficiently fast for measurements without disrupting the integrity of the $\mathrm{T} 1$ center. Bleaching under these conditions was gradually observed over time (Fig. S14). The large ratio of the extinction factors at 628 and $420 \mathrm{~nm}\left(\varepsilon_{620} / \varepsilon_{420}>10\right)$ in the H117G NHC mutant is diagnostic for a $\mathrm{T} 1 \mathrm{Cu}$ center and supports $\mathrm{C}$-bonding of the carbene (Fig. 3). Coordination of the dimethylimidazolium carboxylate precursor via an oxygen donor, i.e. assuming the 
decarboxylation had not taken place, can be dismissed as carboxylate bonding in $\mathrm{H} 117 \mathrm{G}$ mutant is well-known to induce a T2 $\mathrm{Cu}$ site with about equal extinction coefficients of $c a .1 .5 \mathrm{mM}$ ${ }^{1} \mathrm{~cm}^{-1}$ at $420 \mathrm{~nm}$ and $625 \mathrm{~nm} \cdot{ }^{[26]}$ We confirmed this UV-vis signature, by adding benzoate as a control to mimic imidazolium carboxylate bonding without decarboxylation. Moreover, sodium benzoate and imidazolium salts such as dimethylimidazolium and trimethylimidazolium tetrafluoroborate did not show any appreciable change in the UV-vis pattern of the $\mathrm{H} 117 \mathrm{G} \sim \mathrm{H}_{2} \mathrm{O}$ protein (Figure S13). Hence, the characteristic UV-vis spectroscopic data of $\mathrm{H} 117 \mathrm{G} \sim \mathrm{NHC}$ strongly support decarboxylation and $\mathrm{Cu}$ coordination via a soft $\mathrm{C}$-donor site.

Mass spectrometry, proved unsuitable for the characterization of the reconstituted mutants $\mathrm{H} 117 \mathrm{G} \sim \mathrm{L}(\mathrm{L}=\mathrm{NMI}$, NHC), presumably because the ionization conditions induce the dissociation of the ligand, irrespective of the technique used (MALDI-TOF, ESI-OrbiTrap). However, frozen solution X-band EPR spectroscopic data provide further support for the coordination of the carbene to the $\mathrm{Cu}$ center in Azu H117G NHC. The restoration of the $\mathrm{T} 1 \mathrm{Cu}(\mathrm{II})$ signal with $\mathrm{g}_{l}=2.2673$ suggests carbene binding to the $\mathrm{Cu}$ center and is almost unaltered when compared to the NMI analogue $\left(\mathrm{g}_{\mathrm{I}}=2.2681\right)$ or the wild type ( $\mathrm{g}$ $=2.2633$; Fig 4a, Table 1). In addition, the hyperfine splitting, $A_{\|}$ $=59.6 \times 10^{-4} \mathrm{~cm}^{-1}$ is diagnostic for a $\mathrm{T} 1 \mathrm{Cu}$ center. It differs significantly from T2 centers generated from Azu H117G when copper is ligated by an O-donor such as water $\left(142.7 \times 10^{-4} \mathrm{~cm}^{-1}\right)$ or a carboxylate $\left(\mathrm{A}_{\|}\right.$between 140 and $\left.160 \times 10^{-4} \mathrm{~cm}^{-1}\right),{ }^{[26]}$ excluding $\mathrm{COO}^{-}$bonding. Selectivity for the decarboxyalation at the $\mathrm{Cu}$ centre is also strongly supported by the lack of any other trace of copper in the EPR spectrum other than those of the $\mathrm{H} 117 \mathrm{G} \sim \mathrm{H}_{2} \mathrm{O}$ (Fig 4a; ca. $2720 \mathrm{G}$ ).

Unambiguous confirmation of an interaction of the carbene ligand with the copper center in the active site was obtained by pulsed EPR spectroscopic measurements when using a NHC precursor that was ${ }^{13} \mathrm{C}$ labelled at the imidazolylidene $\mathrm{C} 2$ position, ${ }^{[30,35]}$ which is expected to bind to the metal center. This
$\mathrm{NH}^{13} \mathrm{C}$ ligand was coordinated to the $\mathrm{H} 117 \mathrm{G}$ mutant as described for the preparation of the $\mathrm{H} 117 \mathrm{G} \sim \mathrm{NHC}$ mutant. While the UV-vis and continuous wave EPR spectroscopic data of the $\mathrm{H} 117 \mathrm{G} \sim \mathrm{NH}^{13} \mathrm{C}$ isotope are once again identical to $\mathrm{NMI}$ and $\mathrm{NHC}$ reconstituted variants (Figure S12), HYSCORE (hyperfine sublevel correlation spectroscopy) experiments performed at $12 \mathrm{~K}$ provided unequivocal evidence for an interaction between the ${ }^{13} \mathrm{C}$ nucleus of the $\mathrm{NH}^{13} \mathrm{C}$ and the copper center. with a hyperfine coupling $\mathrm{A}_{\perp}\left({ }^{13} \mathrm{C}\right)=1.5( \pm 1) \mathrm{MHz}$ (Fig S17). No benchmark for carbene ${ }^{13} \mathrm{C}-\mathrm{Cu}$ (II) hyperfine coupling is available, however, a cyanide ${ }^{13} \mathrm{C}-\mathrm{Cu}(\mathrm{II})$ hyperfine and also a ${ }^{14} \mathrm{~N}-\mathrm{Cu}(\mathrm{II})$ hyperfine in copper enzymes were reported to be $>20 \mathrm{MHz} \cdot{ }^{[36,37]}$ The relatively small coupling observed here is presumably due to electronic and geometrical constraints, yet it demonstrates unambiguously that the carbene ligand is located in the Azu active site.

While spectroscopic distinction between the C- and the Nbonding mode of an imidazole-derived heterocycle is ambiguous, the electrochemical behaviour is remarkably different upon NHC incorporation; the cathodic reduction potential of $\mathrm{H} 117 \mathrm{G} \sim \mathrm{NHC}$ is diminished by ca. $200 \mathrm{mV}$ and occurs at $+0.15 \mathrm{~V}$ vs NHE, compared to the $+0.33 \mathrm{~V}$ measured for the WT or H117G NMI mutant (Table 1, Fig. 4b). The anodic oxidation is shallow for WT and mutants, as noted previously, ${ }^{[38]}$ and the irreversibility of the redox process is in line with observations for model $\mathrm{Cu}$ complexes, ${ }^{[34]}$ as well as for reconstituted Azu mutants. ${ }^{[26]}$ The stabilization of reduced copper(I) in the presence of a carbene as opposed to copper(II) with a NMI ligand has been previously noted in model systems and provides a rationale for the gradual fading of the blue color of $\mathrm{H} 117 \mathrm{G} \sim \mathrm{NHC}$ samples when stored for prolonged periods of time. This distinct electrochemical behaviour provides further support for carbene bonding to the copper center.

The more facile electron transfer in the $\mathrm{H} 117 \mathrm{G} \sim \mathrm{NHC}$ variant suggests a great potential for NHC ligands to be used in enzyme models in order to mimic and activate electron transfer
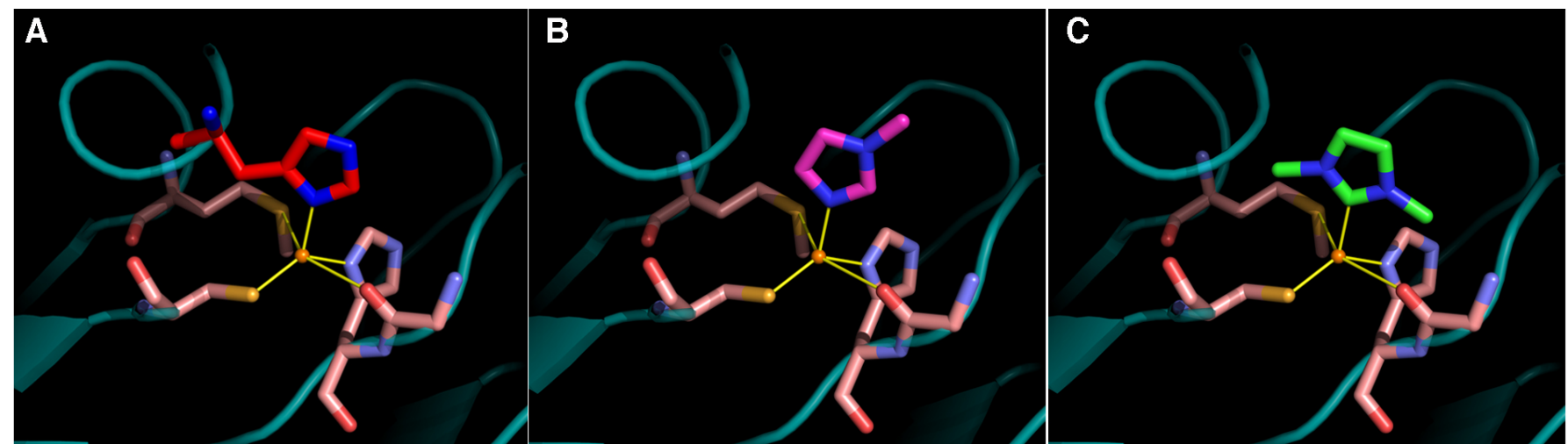

Fig 3. Pymol generated model representations of the Cu site of azurin wild type with a coordinated His at position 117 (panel A), of the His117Gly mutant that features restored activity from coordination of an extraneous N-methylimidazole (NMI; panel B), and of the His117 NHC mutant with coordination of an extraneous dimethylimidazol-2-ylidene (panel C).

Table 1. Spectroscopic and electrochemical data for azurin wild-type and $\mathrm{H} 117 \mathrm{G}$ mutants containing $\mathrm{H}_{2} \mathrm{O}$, $\mathrm{NMI}$ and $\mathrm{NHC}$ as exogenous ligands.

\begin{tabular}{|c|c|c|c|c|c|}
\hline & & AzuWT & $\mathrm{H} 117 \mathrm{G} \sim \mathrm{H}_{2} \mathrm{O}$ & $\mathrm{H} 117 \mathrm{G} \sim \mathrm{NMI}$ & $\mathrm{H} 117 \mathrm{G} \sim \mathrm{NHC}$ \\
\hline UV-vis[a] & $\lambda_{\max }(\varepsilon)$ & $628(5.8)$ & $\begin{array}{l}625(1.3) \\
420(1.9)\end{array}$ & $630(4.4)$ & 629 (3.9) \\
\hline EPR [b] & $\begin{array}{l}g_{11}, g_{22}, g_{33} \\
A_{11}, A_{22}, A_{33} \\
a_{\text {iso }}\end{array}$ & $\begin{array}{l}2.0418, \quad 2.0476, \quad 2.2633 \\
10.4, \quad 15.3, \quad 54.7 \\
26.8\end{array}$ & $\begin{array}{ll}2.019, & 2.0606, \quad 2.2813 \\
24.5, & 6.7, \quad 142.7 \\
58.0 & \end{array}$ & $\begin{array}{l}2.0358, \quad 2.0491, \quad 2.2681 \\
11.9, \quad 6.7, \quad 57.4 \\
25.3\end{array}$ & $\begin{array}{l}2.0374, \quad 2.0483, \quad 2.2673 \\
\begin{array}{ll}9.9, \quad 6.7, \quad 59.6 \\
25.4\end{array}\end{array}$ \\
\hline redox[c] & $E$ & +0.331 & +0.357 & +0.341 & +0.145 \\
\hline
\end{tabular}

[a] UV-vis spectra: $\lambda_{\max }$ in $\mathrm{nm}$ (extinction coefficient $\varepsilon$ in $\mathrm{mM}^{-1} \mathrm{~cm}^{-1}$ ); [b] EPR spectra: samples were supplemented with $50 \% \mathrm{v} / \mathrm{v}$ glycerol and run at $77^{\circ} \mathrm{K}$, (hyperfine $\mathrm{A}$ in $10^{-4} \mathrm{~cm}^{-1}$ and as absolute value $\mid \mathrm{A}_{\mathrm{xx}} \mathrm{I}$ ); [c] redox potential measured by differential pulse voltammetry, values in $\mathrm{V} v \mathrm{NHE}$, scan rate $10 \mathrm{mV} \mathrm{s}^{-1}$. In all cases, the protein samples $(1 \mathrm{mM})$ were measured in $10 \mathrm{mM}$ MES buffer pH 6. For H117G NMI and H117G NHC

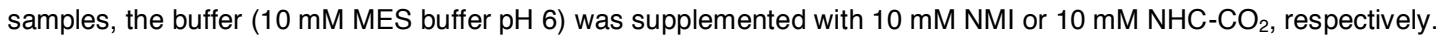


a) intensity /a.u.

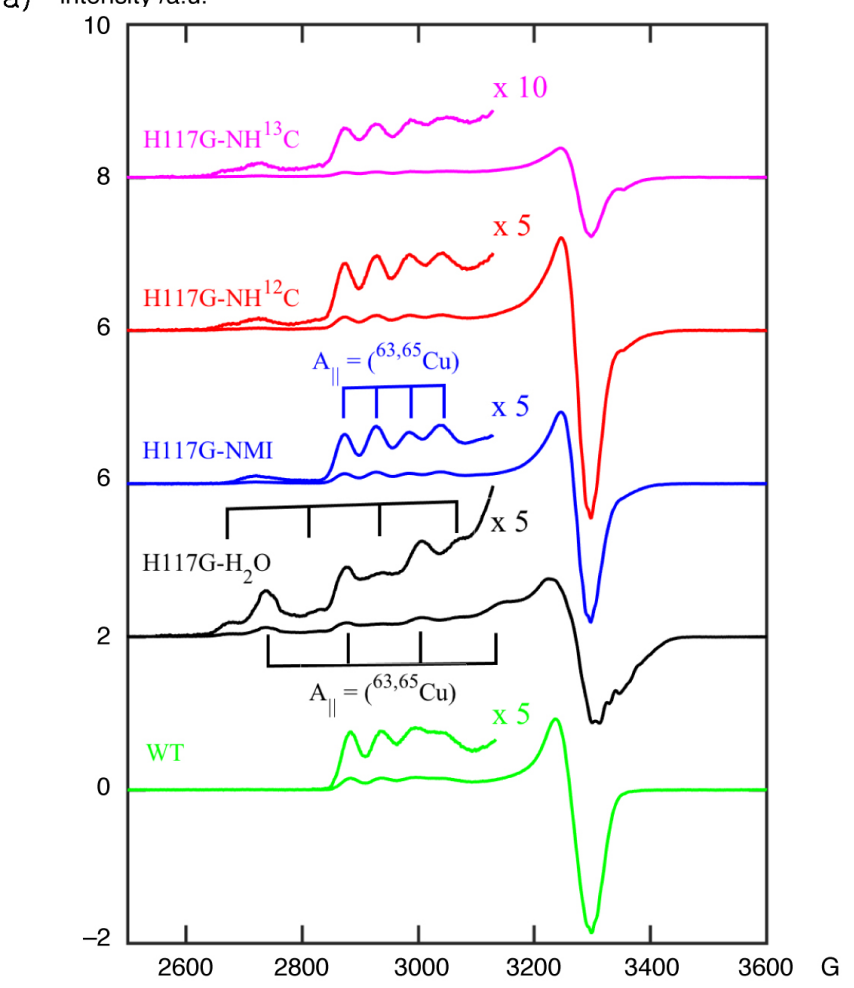

b)

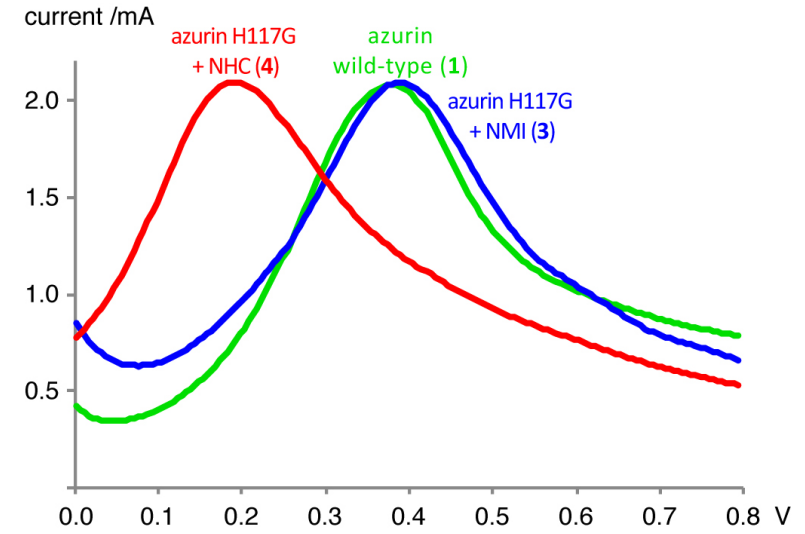

Figure 4. Spectroscopic and electrochemical properties of the H117G NHC system compared to WT: a) Frozen solution X-band EPR spectra at $20 \mathrm{~K}$ of the NHC (red) and NMI restored mutants (blue) showing the same pattern as the WT (green), but significantly different from the $\mathrm{T} 2$ system in the $\mathrm{H} 117 \mathrm{G} \sim \mathrm{H}_{2} \mathrm{O}$ mutant (black) with coordinated water molecule(s). b) DPV section (reduction mode) illustrating the significant shift in the reduction potential upon coordination of the NHC ligand (potentials $\mathrm{E}$ vs normal hydrogen electrode, $\mathrm{NHE}$ ). In all cases, the protein samples $(1 \mathrm{mM})$ were measured in $10 \mathrm{mM}$ MES buffer $\mathrm{pH}$ 6. For $\mathrm{H} 117 \mathrm{G} \sim \mathrm{NMI}$ and $\mathrm{H} 117 \mathrm{G} \sim \mathrm{NHC} / \mathrm{NH}^{13} \mathrm{C}$ samples, the buffer (10 $\mathrm{mM}$ MES buffer $\mathrm{pH}$ 6) was supplemented with $10 \mathrm{mM} \mathrm{NMI}$ or $10 \mathrm{mM}$ $\mathrm{NHC}-\mathrm{CO}_{2} / \mathrm{NH}^{13} \mathrm{C}-\mathrm{CO}_{2}$, respectively.

processes. In fact, it might now be postulated that histidine tautomerizes from a classical $N$-donor coordination mode to a carbene-type $C$-donor mode in the activated state of the enzyme. While such so-called NH,NH-carbenes have been shown to be stable in palladium and platinum complexes, ${ }^{[39]}$ the carbene derived from a $C$-bound histidine is likely only short-lived in biological systems because of isomerization back to the wellestablished $N$-bonding mode in the presumptive resting state. Density functional theory calculations have predicted that the $C$ bound form of imidazole can be energetically favored over the $N$ - bound form depending on the metal and ancillary ligands, ${ }^{[40,41]}$ and both isomerization processes have been observed in small molecule complexes, e.g. switching from $C$ - to $N$-coordination at iridium, ${ }^{[42-44]}$ and vice versa at molybendum and iron. ${ }^{[45-49]}$ The latter isomerization process has been suggested to involve a wagging process that would be plausible also for azurin, i.e. exchange of the ligating site of the imidazole heterocycle from $\mathrm{N}_{\delta}$ to $C_{\varepsilon}$ (Scheme 2). Even though in small molecules, the distinct bonding modes result in diagnostic spectroscopic changes, ${ }^{[23,50]}$ our results here demonstrate that in a metalloenzyme system, the two bonding modes are indistinguishable by UV-vis and cw-EPR spectroscopies. Yet in terms of activity, significant changes are noted as shown here with a unique electrochemical signature of the NHC-rescued H117G mutant.

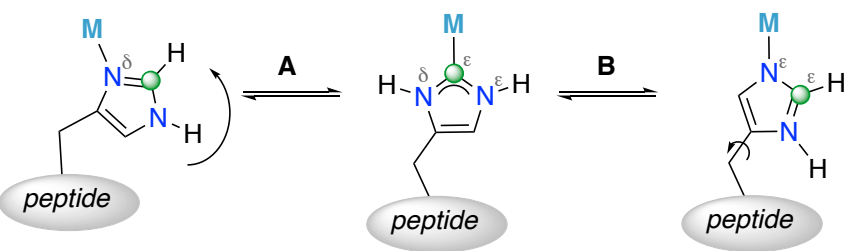

Scheme 2. Potential pathways for isomerization of His from classical $\mathrm{N}$ - to $\mathrm{C}$-coordination mode in a metal coordination environment; $\mathbf{A}$ wagging (black curly arrow) exchanges $N_{\delta}$ to carbenic bonding; $B$ rotation about the peptidic $\mathrm{C}_{\beta}-\mathrm{C}_{\gamma}$ bond of histidine interconverts $\mathrm{N} \varepsilon$ bonding into carbenic coordination.

Based on the observed modulation of the activity of azurin, a carbene bonding mode of His117 therefore complements other approaches to rationalize the unusually large redox potential range that cupredoxins span. Previous rationales have included modification of the Met121 residue, or changes in the secondary coordination sphere which modulate the hydrophobicity and hydrogen-bonding around the metal site. ${ }^{[19-22]}$

Similar isomerization from an $N$ - to a $C$-coordinating bonding mode of the His side chain may be operational in other metalloenzyme-mediated transformations and may be promoted by a locally basic environment. The potential for such a transformation suggests an unprecedented role of histidine in metalloenzymes with fundamental consequences on the understanding of their mode of action. In particular, catalytic oxidation processes benefit significantly from such a change of ligand coordination, as different metal oxidation states are stabilized in $\mathrm{N}-$ vs $C$-bonding of the imidazole heterocycle. His bonding in a carbenic mode rather than through $\mathrm{N}$-coordination is a factor that should be considered when the metal center is located in a less typical distance from the imidazole ring, or when trans located ligands display unusual structural features, especially in a basic local environment, ${ }^{[51,52]}$ though it is more likely that the Nto C-bonding switch is transient and only relevant when the enzyme is in its active mode.

While the potentially transient nature of such $C$-bound intermediates and the spectroscopic similarity of $C$ - and $N$-bound His units may make the detection of a $C$-bound His a difficult task, our work indicates that caution is needed when assuming $\mathrm{N}$ bonding of His as a default. Morevoer, these results offer alternative opportunities in the design of bio-inspired synthetic systems mimicking oxidases in particular, ${ }^{[53]}$ and for related enzymes that require high-valent metal intermediates.

Received: ((will be filled in by the editorial staff))

Published online on ((will be filled in by the editorial staff)) 
Keywords: metalloenyzme $\cdot$ histidine $\cdot$ bonding mode $\cdot \mathrm{N}$ heterocyclic carbene $\cdot$ electron transfer processes

[1] D. Bourissou, O. Guerret, F. P. Gabbaï, G. Bertrand, Chem. Rev. 2000, 100, 39-92.

[2] W. A. Herrmann, Angew. Chem. Int. Ed. 2002, 41, 1290-1309.

[3] M. Poyatos, J. A. Mata, E. Peris, Chem. Rev. 2009, 109, 36773707.

[4] M. Melaimi, M. Soleilhavoup, G. Bertrand, Angew. Chem. Int. Ed. Engl. 2010, 49, 8810-8849.

[5] F. E. Hahn, M. C. Jahnke, Angew. Chem. Int. Ed. 2008, 47, 31223172 .

[6] P. Chábera, Y. Liu, O. Prakash, E. Thyrhaug, A. El Nahhas, A. Honarfar, S. Essén, L. A. Fredin, T. C. B. Harlang, K. S. Kjær, et al., Nature 2017, 543, 695-699.

[7] L. Mercs, M. Albrecht, Chem. Soc. Rev. 2010, 39, 1903-1912.

[8] K. M. Hindi, M. J. Panzner, C. A. Tessier, C. L. Cannon, W. J. Youngs, Chem. Rev. 2009, 109, 3859-3884.

[9] W. Liu, R. Gust, Chem. Soc. Rev. 2013, 42, 755-773.

[10] C. Mayer, D. G. Gillingham, T. R. Ward, D. Hilvert, Chem. Commun. 2011, 47, 12068.

[11] P. Dydio, H. M. Key, A. Nazarenko, J. Y.-E. Rha, V. Seyedkazemi, D. S. Clark, J. F. Hartwig, Science 2016, 354, 102106.

[12] F. H. Arnold, Angew. Chem. Int. Ed. 2017, 2-8.

[13] S. J. Lippard, J. M. Berg, Principles of Bioinorganic Chemistry, University Science Books, Mill Valley, CA, 1994.

[14] A. Sigel, H. Sigel, R. K. O. Sigel, Metal Ions in Life Science, Royal Society Of Chemistry, London, UK, 2009.

[15] M. Costas, M. P. Mehn, M. P. Jensen, L. Que Jr., Chem. Rev. 2004, 104, 939-986.

[16] E. Kovaleva, J. Lipscomb, Science 2007, 316, 453-457.

[17] J. F. Berry, E. Bill, E. Bothe, S. D. George, B. Mienert, F. Neese, K. Wieghardt, Science 2006, 312, 1937-1941.

[18] T. A. Betley, J. C. Peters, J. Am. Chem. Soc. 2004, 126, 62526254.

[19] K. M. Lancaster, S. D. George, K. Yokoyama, J. H. Richards, H. B. Gray, Nat. Chem. 2009, 1, 711-715.

[20] E. I. Solomon, R. K. Szilagyi, S. DeBeer George, L. Basumallick, Chem. Rev. 2004, 104, 419-458.

[21] N. M. Marshall, D. K. Garner, T. D. Wilson, Y.-G. Gao, H. Robinson, M. J. Nilges, Y. Lu, Nature 2009, 462, 113-116.

[22] C. Dennison, Coord. Chem. Rev. 2005, 249, 3025-3054.

[23] K. M. Clark, Y. Yu, N. M. Marshall, N. A. Sieracki, M. J. Nilges, N. J. Blackburn, W. A. van der Donk, Y. Lu, J. Am. Chem. Soc. 2010, 132, 10093-10101.

[24] J. J. Warren, J. R. Winkler, H. B. Gray, FEBS Lett. 2012, 586, 596-602.

[25] H. Nar, A. Messerschmidt, R. Huber, M. van de Kamp, G. W. Canters, J. Mol. Biol. 1991, 221, 765-772.

[26] T. Den Blaauwen, G. W. Canters, J. Am. Chem. Soc. 1993, 115, 1121-1129
[27] A. Monney, M. Albrecht, Chem. Commun. 2012, 48, 10960 10962.

[28] M. Van de Kamp, F. C. Hali, N. Rosato, A. F. Agro, G. W. Canters, Biochim. Biophys. Acta - Bioenerg. 1990, 1019, 283-292.

[29] T. Den Blaauwen, G. W. Canters, J. Am. Chem. Soc. 1991, 113, 5050-5052.

[30] See the supporting information for more details.

[31] C. Hammann, G. van Pouderoyen, H. Nar, F.-X. G. Rüth, A. Messerschmidt, R. Huber, T. den Blaauwen, G. W. Canters, J. Mol. Biol. 1997, 266, 357-365.

[32] A. M. Voutchkova, L. N. Appelhans, A. R. Chianese, R. H. Crabtree, J. Am. Chem. Soc. 2005, 127, 17624-17625.

[33] J. D. Holbrey, W. M. Reichert, I. Tkatchenko, E. Bouajila, O. Walter, I. Tommasi, R. D. Rogers, Chem. Commun. 2003, 28-29.

[34] E. Wyer, G. Gucciardo, V. Leigh, H. Müller-Bunz, M. Albrecht, J. Organomet. Chem. 2011, 696, 2882-2885.

[35] M. Ali, A. Gual, G. Ebeling, J. Dupont, ChemCatChem 2014, 6, 2224-2228.

[36] P. H. Haffner, J. E. Coleman, J. Biol. Chem. 1973, 248, 66266629.

[37] M. M. Werst, C. E. Davoust, B. M. Hoffman, J. Am. Chem. Soc. 1991, 113, 1533-1538.

[38] A. Vila, C. O. Fernandez, Handbook of Metalloproteins, Marcel Dekker, Amsterdam (NL), 2001.

[39] F. E. Hahn, Chem CatChem 2013, 5, 419-430.

[40] G. Sini, O. Eisenstein, R. H. Crabtree, Inorg. Chem. 2002, 41, 602-604.

[41] L. J. L. Häller, S. A. Macgregor, Eur. J. Inorg. Chem. 2009, 20002006.

[42] S. Burling, M. F. Mahon, R. E. Powell, M. K. Whittlesey, J. M. J. Williams, J. Am. Chem. Soc. 2006, 128, 13702-13703.

[43] X. Wang, H. Chen, X. Li, Organometallics 2007, 26, 4684-4687.

[44] T. Kösterke, J. Kösters, E. U. Würthwein, C. Mück-Lichtenfeld, C. Schulte To Brinke, F. Lahoz, F. E. Hahn, Chem. Eur. J. 2012, 18, 14594-14598.

[45] R. J. Sundberg, R. F. Bryan, I. F. Taylor, H. Taube, J. Am. Chem. Soc. 1974, 96, 381-392.

[46] J. Ruiz, B. F. Perandones, J. Am. Chem. Soc. 2007, 129, 92989299.

[47] J. Ruiz, B. F. Perandones, Chem. Commun. 2009, 2741-2743.

[48] M. A. Huertos, J. Pérez, L. Riera, A. Menéndez-Velázquez, J. Am. Chem. Soc. 2008, 130, 13530-13531.

[49] C.-H. Hsieh, R. Pulukkody, M. Y. Darensbourg, Chem. Commun. 2013, 49, 9326-9328.

[50] J. L. Hess, C.-H. Hsieh, J. H. Reibenspies, M. Y. Darensbourg, Inorg. Chem. 2011, 50, 8541-8552.

[51] G. S. Kachalova, A. C. Shosheva, G. P. Bourenkov, A. A. Donchev, M. I. Dimitrov, H. D. Bartunik, J. Inorg. Biochem. 2012, 115, 174-181.

[52] Y. Matoba, N. Bando, K. Oda, M. Noda, F. Higashikawa, T. Kumagai, M. Sugiyama, J. Biol. Chem. 2011, 286, 30219-30231.

[53] L. Que, W. B. Tolman, Nature 2008, 455, 333-40. 


\section{Carbene bonding in enyzmes}

Matteo Planchestainer, Nathalie Segaud, Muralidharan Shanmugam, Jonathan McMaster, Francesca Paradisi, Martin Albrecht

Page - Page

Carbene bonding in cupredoxin: replacement of a histidine ligand in the active site substantially alters copper redox properties

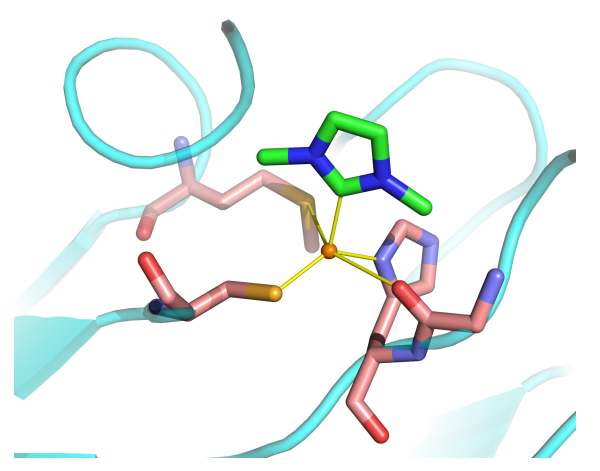

A new view: Insertion of a $\mathrm{N}$ heterocyclic carbene ligand as substitute of a His in the azurin active site reconstitutes the $\mathrm{T} 1$ copper center and is spectroscopically barely distinguishable from $\mathrm{N}$-bonding of $\mathrm{His}$ or $\mathrm{N}$-methylimidazole, but substantially lowers the reduction potential of the copper center and hence facilitates electron transfer processes. 